\title{
Community Structure and Mechanisms of Co-existence among Six Guild Insect Species in the Munessa Forests
}

\author{
Solomon Ayele Tadesse ${ }^{1,2^{*}}$ \\ ${ }^{1}$ Department of Natural Resources Management, College of Agriculture and Natural Resource Sciences, Debre Berhan University, P.O. Box 445, Debre Berhan, Ethiopia \\ ${ }^{2}$ Durham Wildlife Trust, Low Barns Nature Reserve, Witton-le-wear, Bishop Auckland, County Durham, UK
}

"Corresponding author: Solomon Ayele Tadesse, Department of Natural Resources Management, College of Agriculture and Natural Resource Sciences, Debre Berhan University, P.O. Box 445, Debre Berhan, Ethiopia, Tel: +251-111-6815440; E-mail: solomon.ayele1972@gmail.com

Received date: April 03, 2018; Accepted date: May 08, 2018; Published date: May 30, 2018

Copyright: ( 2018 Tadesse SA. This is an open-access article distributed under the terms of the Creative Commons Attribution License, which permits unrestricted use, distribution, and reproduction in any medium, provided the original author and source are credited.

\begin{abstract}
Anthropogenic disturbances are major factors influencing the ecological processes and spatial patterns of a landscape. Most studies which were conducted in the past in the field of landscape ecology were carried out based on the analyses of spatial patterns. However, considering only the spatial patterns is more of descriptive and incomplete. The present study utilized the analyses of both spatial patterns and ecological processes in a landscape scale. The objective of the study was to examine the impacts of logging and other human-induced disturbances on community structure and mechanisms of co-existence among six guild insect species in a landscape scale between 1970 and 2010 in the Munessa Forests. Mathematical model was employed to compute the index values of richness, patchiness, diversity, dominance, and contagion. Moreover, counting was done to determine the number of boxes in each habitat type using box fractal dimension technique. The box fractal dimension was analyzed by regressing the number of boxes counted versus caliber width. Survival and intrinsic rate of population growth for each coexisting species were determined. The results revealed that logging and other human-induced disturbances affected the index values of patchiness, diversity, dominance, and contagion, suggesting that the size of each habitat type and patterns of habitat patches differed between 1970 and 2010. Moreover, the box fractal analysis showed that there was a change in habitat size and patterns of species distribution resulted from the negative impacts of logging and other human-induced disturbances. The stochastic process results suggested that anthropogenic disturbances affected the survival, intrinsic rate of population growth, and co-existence among the six guild insect species through affecting the natural mosaics of habitats and also by aggravating the stochastic causes of species extinction rates. Generally, the combined results obtained from the change in spatial patterns and ecological processes are important to describe and better explain how logging and other human-induced disturbances affected the community structure and mechanisms of coexistence among the six guild insect species in a landscape scale between 1970 and 2010. The findings of this study are crucial to explain and increase our understanding and later predict how the impacts of logging and other human-induced disturbances affect the structure and coexistence of the six guild insect species in a landscape scale. The "Anti-fragmentation Authority" should properly work towards conserving and managing the patches of the four habitat types which are connected one another. Because connectedness increases the dispersal rates of individuals from one habitat patch to another. Edge effect will be also reduced when compacted habitat patches are connected for future conservation goals.
\end{abstract}

Keywords: Anthropogenic disturbances; Box fractal dimension; Contagion; Diversity; Dominance; Extinction; Fragmentation; Patchiness; Richness

\section{Introduction}

Landscape ecology emphasizes on broad spatial and temporal scale[1]. The ecological effects of the spatial patterning of ecosystems focus on the development and dynamics of spatial heterogeneity, interactions and exchanges across heterogeneous landscapes, the influences of spatial heterogeneity on biotic and abiotic processes, and management of spatial heterogeneity [2-5]. Landscapes can be observed from many points of view, and ecological processes in landscapes can be studied at different spatial and temporal scales [1,2,6-8]. Due to the existence of environmental heterogeneity [4] and processes interacting at different spatial and temporal scales $[7,8]$, ecological patterns at large scales take into consideration of high complexity $[3,5,9,10]$. This is because landscape complexity has not been shown to be constant across a wide range of spatial and temporal scales $[4,7,11]$. This lack of constancy probably reflects the effects of processes that operate at different scales $[12,13]$; however, it remains a focus of current research in landscape ecology $[3,14]$.

Environments often offer diverse spatial heterogeneities of hazards and opportunities that vary with spatial and temporal scales $[5,6,11,12,15,16]$. Those heterogeneities can occur across space (i.e. within a foraging patch, home range, and landscape) $[3,5,6,17]$. Thus, landscape heterogeneity increases the probability to have more number of habitats $[3,5,18]$, which ultimately leads to an increase in the survival and coexistence of different guild species in a biotic community. Habitat variability also affects species relative abundance and presence in a community and represents a strong structuring force for communities $[18,19]$. Theoretical studies also predict a positive correlation between the viability of wild animal populations and habitat diversity and landscape heterogeneity $[4,5,7,12]$. Thus, the number of different habitats, habitat size, and distribution of the habitat patches in the landscape would affect habitat heterogeneity $[3,5,7,18]$. Habitat diversity affects the structure and mechanisms of species coexistence in biotic communities because different species 
may specialize on different habitat types and niche regimes [20,21]. For example, the presence of new habitats may change the habitat selection of a species and may create more opportunities for coexistence $[5,22]$.

Communities are not static entities but change in species composition and abundances, both in space and time over the landscape $[7,18]$. Spatial patterns within a natural community, generated by a variety of extrinsic and intrinsic factors, clearly influence apparent and emergent aspects of that assemblage [23] Models of competition with explicit resource dynamics predict similar phenomena if each species has a greater impact on the resource that most limit its own growth [24]. Moreover, different parts of the environment represent habitats of varying quality, in terms of costs and benefits, for different organisms [25]. In most cases, habitat diversity and landscape heterogeneity have positive effects on the availability of different habitat resources $[5,18]$. These may allow different species of a community in the natural system to coexist together through spatial or temporal partitioning of common habitat resources. For example, desert granivorous rodent communities use different mechanisms of coexistence, which may contribute to their diversities in the desert ecosystems $[5,18,20,21,26]$. Among the many, spatial or temporal partitioning of habitat resources at various scales could be mentioned as a forefront to allow coexistence among different species of gerbil community in the desert ecosystem [26].

A continuing challenge in ecology is disentangling the relative role of deterministic processes from chance, historical factors in structuring ecological communities [3,4,26]. Many ecological models of local species interactions in a community predict the occurrence of priority effects due to alternative stable equilibrium [27]. For example, the proponents of the species pool hypothesis suggested that many communities are unsaturated and that local species richness is, therefore, limited by the availability of colonists from the landscape or regional species pools [28]. An alternative approach is to view the community as a spatial and temporal mosaic of such small-scale systems, recognizing that the individual component "patches" cannot be viewed as closed [23]. Rather, they are part of an integrated "patchwork" with individual patches constantly exchanging materials directly or indirectly through a patch [23]. Disturbance, often in the form of extinctions due to natural catastrophe, competition, or predation-related agents, interrupts the local march to and survival of equilibrium (i.e. local climax) [23]. Thus, the overall system patterning must be understood in terms of a balance reached between extinctions and colonization abilities of the various species of the community.

Human-derived disturbances are becoming complex and dynamic problems, which need to be emphasized and addressed in landscape ecology as major factors affecting the ecological processes and patterns both at local and regional scales $[1,3,23]$. It has been suggested that human-influenced landscapes exhibit simpler patterns than natural landscapes, as measured by the fractal dimension [14]. Landscapes influenced by natural rather than anthropogenic disturbances may respond differently, with natural disturbances increasing landscape complexity. Thus, chronic human disturbances affect the community structure, function, and species coexistence through victimizing the quality and quantity of the natural mosaic habitats over the landscape. For example, [29] noted that low levels of habitat and landscape fragmentation may result in ill-functioning communities while greater fragmentation may result in species losses and ultimately in the loss of whole communities. Moreover, human disturbances affect the connectivity of natural mosaic habitat patches and thereby hinder the free movement of organisms across the landscape. Greater problems arise when considering the ways interacting species, or whole communities, integrate landscapes [30]. Thus, human disturbances are processes which are scale-dependent whose effects on the landscape as well as on the habitat patches depend on the scale at which we evaluate the anthropogenic impacts on the structure, species diversity, distribution, abundance, and interactions of a biotic community across the landscape.

Logging and other human-induced disturbances, such as free-range livestock grazing and agricultural expansion are the common problems affecting the biodiversity found in the Munessa Forests [31,32]. Previous studies suggested that logging and other human-induced disturbances can affect community structure and mechanisms of coexistence among different guild species $[1,3,6]$. Ecological processes often not only affect spatial patterns, but also they are affected by the spatial patterns of landscapes $[1,4,12]$. Following $[1,14,20,21,26]$, this study combined the analyses of data on spatial patterns (e.g. richness, patchiness, diversity, dominance, connectedness, and box fractal dimension) and ecological processes (e.g. dispersal rate, stochasticity threshold, and intrinsic rate of population growth) which ultimately increase our understanding on the ecological processes and spatial patterns in a landscape scale. Thus, the objective of the study was to examine the impacts of logging and other human-induced disturbances on community structure and mechanisms of coexistence among six guild insect species (i.e. Dysgonia torrid - family Noctuidae, order Lepidoptera, Dugaria mendax - family Noctuidae, order Lepidoptera, Hypocctla deflorata - family Noctuidae, order Lepidoptera, Ophiusa tirhaca - family Erebidae, order Lepidoptera, Pantydia dufayi - family Erebidae, order Lepidoptera, and Serrodes partita - family Erebidae, order Lepidoptera; hereafter species 1,2,3,4,5, and 6 , respectively) in a landscape scale over two assessment periods (i.e. 1970 and 2010) in the Munessa Forests.

The major host plants for the six insect species in the Munessa Forests (i.e. the study site) include Acokanthera schimperi, Adhatoda schimperiana, Afrocarpus falcatus, Albizia gummifera, Aningeria adolfi-friederici, Bersama abyssinica, Buddleja polystachya, Carissa edulis, Celtis Africana, Croton macrostachyus, Ekebergia capensis, Hagenia abyssinica, Prunus Africana, Syzygium guineense, Millettia ferruginea, and Teclea nobilis. As to their ecological associations, species 1, 2 and 3 mostly roost on the branches of trees and shrubs, but they also rest on the stem barks of the host plants. However, species 4 , 5 and 6 usually roost on the stem barks of the host plants while they were sometimes seen perching on the branches of the host trees, shrubs and even on tall grasses.

As the local people in the nearby areas of the Munessa forests cut trees for various purposes including fuel wood, construction materials, selling forest products, and practicing free-range grazing, they are disturbing the communities of insects and their habitats in the study site. Moreover, the human induced disturbances can affect the insects' nesting site, reproductive success and may also increase their proneness to risks of predation by their potential predators including birds. In this study, the following two research questions were addressed: (1) How do index values (e.g. richness, patchiness, diversity, dominance, and contagion), box fractal analysis, dispersal rate, stochasticity threshold, and intrinsic rate of population growth help to understand and predict the change in spatial patterns and ecological processes over a landscape? (2) How do logging and other humaninduced disturbances affect community structure and mechanisms of coexistence among six guild insect species in a landscape scale? 


\section{Materials and Methods}

\section{Study area}

The study was conducted in the Munessa Forests, south-eastern Ethiopia. The Munessa Forests are situated in Oromiya Administrative Regional State at $7^{\circ} 13 \mathrm{~N}, 38^{\circ} 37 \mathrm{E}$. The altitude range extends from 2100 to $2700 \mathrm{~m}$ asl. Munessa has a distinct wet and dry season. The mean annual rainfall is about $1250 \mathrm{~mm}$. The mean annual temperature varies from $15^{\circ} \mathrm{C}$ to $20^{\circ} \mathrm{C}$. The vegetation is composed of natural and plantation forests where the main forest blocks are found on the escarpment and associated plateau lying between the Rift Valley lakes and the eastern edge of the Rift Valley [31-33].

\section{Index values}

Understanding environmental heterogeneity requires the appropriate analysis of the spatial distribution of elements, for example, habitat patches in the landscape [34]. Thus, the development of landscape-oriented indices is crucial to analyse those elements within a landscape (i.e. the composition) as well as the configuration (pattern) of a whole particular landscape [3,10,34]. For example, the use of complementary landscape indices (e.g. dominance, contagion, and fractal dimension) in the eastern United States discriminated between major landscape types, such as urban coastal, mountain forest, and agricultural areas [1,3,8,9,34]. These three indices also appeared to provide information at different scales, where the fractal dimension and dominance indices reflected broad-scale pattern while the contagion index reflected the fine-scale attributes that incorporate the adjacency of different habitats $[2,8,34]$. Thus, both classical and adopted ecological methods are important techniques to quantify the index values of different elements and calculate box fractal dimension $[3,34]$ of a landscape over the two assessment periods (i.e. 1970 and 2010).

Landscape indices are ecologically relevant so that they reflect important attributes of spatial pattern [35]. For example, landscape indices derived from information theory have been applied in several ecological studies $[2,8,9,10,11]$. Mathematical formulae were employed to compute the different index values (i.e. indices) of richness, patchiness, diversity, dominance, and contagion in the two assessment periods (i.e. 1970 and 2010) over the landscape of the Munessa Forests.

Accordingly, number of cells and boundaries of cells were counted depending on the nature of the index whose value is required to be quantified.

Richness for each landscape was calculated with the formula $\mathrm{R}=$ $(\mathrm{H} / \mathrm{Hmax}) \times 100 \%$.

Where, $\mathrm{H}$ is the number of habitat types present and Hmax is number of habitat types possible.

$$
\text { Patchiness was calculated as: } \mathrm{P}=\sum_{i=1}^{N b} D s \mathbf{N}_{\mathbf{b}}
$$

Where, $\mathrm{Nb}$ is the number of boundaries between adjacent cells and Ds is a dissimilarity value for the ith boundary between adjacent cells.

Note: To determine the patchiness index for each landscape, I counted all the boundaries between adjacent cells of each habitat type. Dissimilarity value may vary depending on our personal judgment $[1,3,6,34]$. However, for this study, I decided the dissimilarity (Ds) value to be 0 when the 2 cells compared are identical and as large as 1 when the 2 cells compared are totally different. Thus, following $[1,3,6,34]$, I decided to have a Ds value of 0.25 between cells of habitat 1 and habitat 2, Ds value of 0.5 between cells of habitat 1 and habitat 3 , Ds value of 1 between cells of habitat 1 and habitat 4 . I also decided to have Ds value of 0.25 between cells of habitat 2 and habitat 3, Ds value of 0.5 between cells of habitat 2 and habitat 4 , Ds value of 0.25 between cells of habitat 3 and habitat 4 .

Diversity (Shannon diversity) was calculated as: $\mathrm{H}^{\prime}=-\sum_{i=1}^{H} P i \ln P i$ Where, $\mathrm{H}$ is the number of habitat types present and $\mathrm{Pi}$ is the proportion of the landscape in the ith habitat.Dominance was calculated as: $\mathrm{D}=\ln \mathrm{H}-\sum_{i=1}^{H} P i \ln P i$ where, $\mathrm{H}$ is the number of habitat types present and $\mathrm{Pi}$ is the proportion of the landscape in the ith habitat.Contagion was calculated as: $\mathrm{C}=2 \mathrm{Hln} \mathrm{H}+\sum_{i=1}^{H} \sum_{j=1}^{H} q i j \ln q i j$ where, $\mathrm{H}$ is the number of habitat types present and qij is the probability of habitat $\mathrm{i}$ being adjacent to habitat $\mathrm{j}$. In other words, $\mathrm{qij}=$ $\mathrm{nij} / \mathrm{ni}$, where nij is the number of cells of habitat type $\mathrm{i}$ adjacent to habitat type $\mathrm{j}$ and $\mathrm{ni}$ is the number of cells of habitat.

\section{Box fractal dimension}

Fractal geometry was introduced as a good method to study shapes that are partially correlated over many scales $[1,3,6,12,34]$. The fractal dimension has also been hypothesized to reflect the scale of the factors causing the spatial pattern $[1,3,6,34,36]$. Quantifying spatial pattern is treated as the first step to understanding ecological processes [1]. Accordingly, I counted to determine the number of boxes (i.e. habitat patches) of each habitat type based on the data for the two assessment periods (i.e. 1970 and 2010). Thus, the box fractal dimension of the two landscapes was calculated by regressing the number of cells counted against caliber width.

\section{The Stochastic process}

The values of dispersal rate, stochasticity threshold, and intrinsic rate of population growth for each species in the four habitats were determined. Based on the average value of intrinsic rate of population growth, the dominance hierarchy for each species was ranked. For example, a species with the highest average value of intrinsic rate of population growth was ranked as the most dominant species in the community. The summary of the values of dispersal rate, stochasticity threshold, intrinsic rate of population growth, and dominance hierarchy for each species in the four habitats.

\section{Results}

\section{Index values}

The results of the different indices (i.e. values of richness, patchiness, diversity, dominance, and contagion) in the two assessment periods (i.e. 1970 and 2010) in the Munessa Forests were as followed. According to the results presented; the following remarks can be made logging and other human-induced disturbances in the core.

Munessa Forests did not affect the index value of habitat richness in 1970 and 2010 though the patterns of the distribution and size of the habitats were affected. This suggested that richness index is not a good descriptor to study the impacts of logging and other human-induced 
disturbances regarding the change in the landscape pattern between 1970 and 2010. However, their negative effects are clearly observed while affecting the index values of patchiness, diversity, dominance, and contagion in the two assessment periods.

The value of patchiness index increased between 1970 and 2010 as is shown in various studies is because logging and other human-induced disturbances converted the connected habitats into fragmented patchy habitats. Moreover, the mix of different habitat types among one another increases the patchiness index in a non-random fashion so that the configuration of the Munessa Forests landscape was changed between 1970 and 2010 .

Habitat diversity index value decreased between 1970 and 2010 because many areas in the Munessa Forests landscape were converted into habitat type 1 due the negative impact of logging and other human-induced disturbances within its. The reduction in the value of habitat diversity index is suggested to be attributed to the decrease in the evenness of the proportion of the different habitat types over the landscape. However, dominance index increased between 1970 and 2010. Furthermore, was suggested to be because of the shrinkage in the area of the three habitat type (i.e. habitat 2, 3, \& 4), but dominated by habitat 1 . Contagion index showed decrement between 1970 and 2010. Furthermore, its was because many of the habitats became fragmented into smaller habitat patches and even some of the cells became isolated on the periphery of the landscape without any connection with the adjacent cells of the other habitat type. The habitats became more susceptible to edge effects when small fragmented habitats are exposed to adjacent cells of other habitat type than one big and compacted habitat patch. As a result, the contagion index value between 1970 and 2010 is a good descriptor to evaluate the change in the spatial pattern of habitat patches.

\section{Box fractal dimension}

The results on the counts of the box fractal dimension of each habitat type between 1970 and 2010 in the Munessa Forests were given as followed. The scale of resolution was found to affect the number of cells (i.e. habitat patches) of each habitat type counted between 1970 and 2010. As shown in various studies, the number of cells of habitat 1 increased between 1970 and 2010 due to the negative impacts of logging and other human-induced disturbances. This suggested that habitat 1 may be a hostile habitat for the six coexisting guild species and it is why we saw zero intrinsic rate of population growth for each of the six guild species. However, the remaining three habitat and their type (i.e. habitat $2,3 \& 4$ ) dramatically decreased in their number of cells (i.e. habitat size) as well as configuration of cells (i.e. pattern of distribution) due to the negative impact of logging and other humaninduced disturbances between 1970 and 2010. For example, as showed the three habitats (i.e. habitat 2, $3 \& 4$ ) became fragmented and patchy in their spatial distributions, which resulted in low connectedness among the cells within each habitat type. This could affect the free movement or dispersal of each guild species from one habitat patch to another. Moreover, the destruction and fragmentation of the habitats aggravated the extinction rates of the six coexisting guild species by increasing the likelihood of stochasticity threshold and also jusitifed. For example, severe competition for the same but very limited habitat resources resulted from the rapid shrinkage in the area of preferred habitats as well as deterioration of habitat quality would likely increase the extinction rates of the six coexisting guild species.

The slope of the box fractal dimension for each habitat type between 1970 and 2010 was shown by regressing the log of caliber width versus the log of cell counts for each habitat type. Compared with habitat 1 , the slope of the box fractal dimension showed a decrease in trend line for the three habitats (i.e. habitat 2, 3, and 4) between 1970 and 2010. For example, compared to the value in 1970, the slope of box fractal dimension of habitat 1 decreased in 2010 and which was also present. This could be due to the increase in the area coverage as well as good connectivity of the cells of habitat 1 over the landscape in 2010.

However, in the case of the three habitats and which shows (i.e.

habitat 2, 3, and 4), the slopes of the box fractal dimension had increased between 1970 and 2010 because each of the three habitats shrank in their areas of coverage (i.e. number of cells).

However, the results generally showed more or less a similar trend of a decrease in the values of slope of the box fractal dimension for each habitat type between 1970 and 2010 when the values of the caliber width increased due to the scale effect.

\section{Results of the Stochastic Process}

Species 1 had a positive intrinsic rate of population growth in habitat 2 so that it may persist well in habitat 2 compared to the other 5 species, which showed either negative, or zero intrinsic rate of population growth in habitat 2 . However, species 1 showed zero intrinsic rate of population growth in habitat 1 , but negative intrinsic rate of population growth in habitat 3 and 4 . As species 1 had low dispersal rate and high stochasticity threshold, suggesting that it is more likely to disappear from habitat 1,3 , and 4 . However, due to its positive intrinsic rate of population growth, the dominance hierarchy of species 1 was the strongest so that it may hopefully exclude the other five species in habitat 2.

Species 2 had a positive intrinsic rate of population growth in habitat 3 so that it may perform well and persist in habitat 3 compared to the other 5 species, which showed either negative or zero intrinsic rate of population growth. Moreover, the dominance hierarchy of species 2 was the strongest compared to species $3,4,5$, and 6 so that it may exclude all those four species and perform better in habitat 3 . However, species 2 showed zero intrinsic rate of population growth in habitat 1, but negative intrinsic rate of population growth in habitat 2 and 4 . As species 2 had low dispersal rate and high stochasticity threshold, suggesting that it is more likely to get extinct from habitat 1 , 2 , and 4 due to the negative impact of logging and other humaninduced catastrophes.

Species 3 had a positive intrinsic rate of population growth in habitat 4 so that it may persist in habitat 4 . Due to its positive intrinsic rate of population growth and strong dominance hierarchy, it is more likely to dominate and exclude species 4,5 , and 6 in habitat 4 . However, species 3 showed a negative intrinsic rate of population growth in habitat 2 and 3 . As species 3 had low dispersal rate and high stochasticity threshold, suggesting that it is more likely to disappear from habitat 1,2 , and 3 .

Species 4 had a positive intrinsic rate of population growth in habitat 4 . However, it showed zero intrinsic rate of population growth in habitat 1,2 , and 3 . As species 4 had high dispersal rate and low stochasticity threshold, suggesting that it is more likely to be favored by the landscape change and can increase in its population size and may exclude species 5 and 6 in habitat 4 or coexist with the other species in all of the four habitats. Even though species 4 showed zero intrinsic rate of population growth in habitat 1,2, and 3, the population will benefit from high dispersal rate and low stochasticity threshold 
catastrophes, such as habitat fragmentation and destruction due to the negative impacts of logging and human-induced disturbances.

Species 5 had a positive intrinsic rate of population growth in habitat 4 . However, it showed zero intrinsic rate of population growth in habitat 1,2 , and 3 . As species 5 had low stochasticity threshold, suggesting that species 5 is more likely to perform better and coexist with the other dominant species in habitat 4 . Even though species 5 had showed zero intrinsic rate of population growth in habitat 1,2 , and 3 , the population may coexist with the other species due to its low stochasticity threshold. As species 5 had low dispersal rate, the likelihood of the population to increase in habitat 1,2 , and 3 is very low from immigration.

Species 6 had a positive intrinsic rate of population growth in habitat 4 so that it may persist well and coexist with the rest of the five guild insect species in habitat 4 . However, species 6 showed zero intrinsic rate of population growth in habitat 1 , but negative intrinsic rates of population growth in habitat 2 and 3 . Next to species 5 , species 6 had the least dominance hierarchy, suggesting that it had low dispersal rate and high stochasticity threshold. Therefore, it is more likely to get extinct from habitat 1,2 and 3. Species 6 was susceptible to the negative impacts of logging and other human-induced disturbances; suggesting that it is more likely to be an endangered species over the landscape. However, it needs further field data through considering additional life-history of species 6 .

All the six species had zero intrinsic rates of population growth in habitat 1 , suggesting that habitat 1 is not a suitable habitat to the six guild insect species, because habitat 1 could be a marginal habitat or inhospitable environment over the landscape. However, species with high dispersal rate (e.g. species 4) studies cause may use habitat 1 as a corridor for its safe movement between or among habitats provided that there is no blocking effect by man or other catastrophe over the landscape.

\section{Discussion}

Diversity and coexistence of guild species in a landscape is an important element, which is shaped not only by the number of species present in the system, but also by the processes that cannot be necessarily observed at a local scale $[6,10,11,13]$. Of course, species diversity at the local scale is determined by the dynamic balance of local colonization and extinction [10,37]. However, species interactions, such as competition for limited common habitat resources among guild species would aggravate the rate of species extinction at the local scale through affecting the mechanisms of coexistence in a community [10]. For example, the rates of extinction are primarily controlled by local ecological processes, such as competitive exclusion, predation, disease, disturbance, demographic, and environmental stochasticity [38]. Thus, as revealed in the present study, indices on diversity and other related elements (e.g. patchiness, dominance, and contagion) [9] are important indicators for conservation and management of communities and their viable habitats at a landscape scale.

Landscape indices are ecologically relevant because they reflect important attributes of spatial pattern where they can functionally link the dynamics of ecological processes to landscape structure $[6,9,11,35]$. Several studies suggested that only a few variables may be required to understand and predict landscape patterns, the spread of disturbances, or ecosystem processes $[2,8,14,11]$. The present study suggested that size and distribution of habitat patches are measures of landscape structure. Moreover, the inclusion or exclusion of habitat patches produces distinctive differences in the landscape mosaic (i.e. the number of recognized patch types) [1]. These characteristics may be of particular importance for species that require habitat patches of a minimum size or specific arrangement $[2,8,10]$. Habitat patches that survive the process of fragmentation become increasingly isolated from one another, and this can cause species' declines in excess of predictions based strictly on reductions in habitat area [9,39]. The change in the mosaics of habitat quality and quantity between 1970 and 2010 showed that the biotic community of the six coexisting guild insect species in the four habitats would be negatively affected by logging and other human-induced disturbances in the Munessa Forests.

The results suggested that destruction and fragmentation of habitats affect the community structure and mechanisms of coexistence among the six guild insect species even at local scale by affecting the natural mosaic habitats on the landscape. For example, logging and other human-induced disturbances were observed to affect the free movement (i.e. dispersal) of the six guild insect species on the landscape due to the effect of fragmentation and exclusive isolation of previously connected habitat patches. Even though the value of richness index remained the same between 1970 and 2010, the landscape had changed in its pattern of habitat configurations. For example, the index values of contagion and patchiness were good descriptors to reveal the negative impacts of logging and other humaninduced disturbances on the landscape. Thus, the result of contagion index showed that patterns of habitat cells (i.e. patches) were affected by logging and other human-induced disturbances in the Munessa Forests. The value of patchiness index also supported the result obtained from the contagion index. For example, due to habitat fragmentation and the mixed patterns of different habitat patches (i.e. cells), the patchiness index increased between 1970 and 2010. Previous studies $[10,40]$ also noted that habitat patchiness affects communities because sub-populations of a species may escape local extinction in a few patches and recolonize those patches at later times.

Shapes and boundaries of the landscape have been quantified by using fractal dimension that provides a measure of the complexity of the spatial patterns of habitats. Fractals have been used to compare simulated and actual landscapes $[6,34,41]$, to compare the geometry of different landscapes $[34,36,41,42]$; and to judge the relative benefits to be gained by changing scales in a model or data set $[1,6,11,43]$. Compared to habitat 1 , the slope of the box fractal dimension of the present study showed a decrease in trend line for the three habitats (i.e. habitat 2, 3, and 4). As compared to 1970, the slope of the box fractal dimension of habitat 1 decreased in 2010 because of the increase in the area coverage as well as good connectivity of the cells of habitat 1 in 2010. However, in the case of the other three habitats (i.e. habitat 2, 3, and 4), the slopes of the box fractal dimension had increased between 1970 and 2010 because each of the three habitats shrank in their areas of coverage (i.e. number of cells). Moreover, the patterns of habitat cells became less connected or more isolated due to the fragmentation of the patches of these three habitats. However, changes in fractal dimension may be difficult to interpret because multiple factors simultaneously affect its value and/or several formulae of fractal dimension produce a wide range of results $[10,14,34,36,41,42]$.

The results from stochastic process suggested that some of the species in the community (e.g. species 6) which recent became endangered. This is because disturbances raised the stochastic causes of species 
Page 6 of 7

extinction rates through increasing the stochasticity threshold. However, certain generalized species, may be native inhabitants of a region, usually benefited from occurring in successional stages [10,38], irrespective of the impact of logging and other human-induced disturbances on other species of a community. For example, species 1 persisted in habitat 2 due to its positive intrinsic rate of population growth and highest dominance hierarchy in the community though it had low dispersal rate and high stochasticity threshold. Thus, species 1 may exclude the other coexisting guild insect species when habitat 2 (i.e. the preferred habitat for species 1) shrinks due to the impact of logging and other human-induced disturbances that may result in reduction and/or limitation of common habitat resources. Compared to other guild insect species in the community, species 2 may persist in habitat 3 due to its positive intrinsic rate of population growth regardless of its low dispersal rate and high stochasticity threshold. Irrespective of their high dominance hierarchies, species 1 and 2 may get extinct from habitat 4 due to their negative intrinsic rate of population growth, low dispersal rate, and high stochasticity threshold.

On the other hand, the stochastic process results suggested that species $3,4,5$, and 6 may persist and coexist in habitat 4 due to their positive intrinsic rates of population growth. However, the area covered by habitat 4 had dramatically decreased and became fragmented over the landscape between the two assessment periods (i.e. 1970 and 2010). For example, compared to the other three habitat types, habitat 4 was the most deteriorated habitat in its size due to the negative impacts of logging and other human-induced disturbances in 2010. Thus, it is difficult for those four species (i.e. species $3,4,5$, and 6) to coexist together because they inevitably face limited habitat resources in habitat 4. At the local scale, previous studies suggested that species interactions mainly competition for limited habitat resources may enforce uniform distribution due to the utilization of body-size dependent resources [5,10,21,44]. However, the present stochastic process results showed that logging and other humaninduced disturbances affected the survival, intrinsic rate of population growth, structure, and coexistence of the six guild insect species through affecting the natural mosaics of habitats as well as aggravating the stochastic causes of species extinction rates. For example, due to logging and other human-induced disturbances, the present study suggested that a hostile habitat which will act as a sink (i.e. habitat 1) increased in its size as well as patch cells distribution. However, few species (e.g. species 4 due to its high dispersal rate and low stochasticity threshold) may be benefited from the change in the configuration of the habitat patches over the landscape.

Conservation strategies frequently consider not only the amounts of habitat that must be retained, but also the spatial configurations of habitats across the landscape of concern $[1,6,11,36,39,42]$. Therefore, the "Anti-Fragmentation Authority" (AFA) should work towards changing and conserving the connected cells (i.e. habitat patches) comprising of the four habitat types which are connected one another. This is because connectedness promotes the dispersal rates of individual species from one habitat patch to another and may allow coexistence among the six guild insect species on the landscape $[10,36,42]$. Moreover, the edge effect will be reduced when compacted cells (i.e. habitat patches) are connected for future conservation goals by the authority.

\section{Conclusion and Recommendation}

The eight cells which were suggested to be set aside for future conservation by the AFA were as shown in various studies. Therefore, I recommended that the red painted eight cells should be converted from habitat 1 to habitat 4 and conserved by the AFA because these eight cells are connected to each other as well as with the other cells (i.e. habitat patches) of the already existing habitat 4 . It is also good to restore the former diversity of the landscape, for example, compared to the other three habitats; habitat 4 was most severely affected by the negative impacts of logging and other human-induced disturbances. The connectedness of the converted cells may, therefore, facilitate the free movement and dispersal of the six guild insect species from one habitat type or patch to another and may also promote species coexistence in a community. Since the eight cells are found in compacted form, it is easier to implement proper conservation and management by AFA. In addition, it reduces the impact of edge effect on each cell (i.e. habitat patch) because identical cells (i.e. habitat patches) share common boundaries. On the degraded areas, multipurpose tree species can be planted and managed so that it creates alternative livelihoods for the local communities. At the same time, these areas buffer the Munessa Forests and also promote sustainable use of natural resources.

\section{Acknowledgement}

First of all, I would like to forward my gratitude to the office of The Arsi Forest Branch for its unreserved co-operation in giving me to access the long-term field data for this study. During this research, the State of Israel provided financial assistance.

\section{Funding}

The author would like to forward his gratitude to the State of Israel for covering all sources of the research funding that helped in the analyses and interpretation of the data and also in writing of the manuscript.

\section{Author's contributions}

SAT analyzed the data, interpreted the results, and wrote the manuscript.

\section{Conflict of interest}

The author declares that there is no competing interest.

\section{References}

1. Li H, Wu J (2004) Use and misuse of landscape indices. Landscape Ecology 19: 389-399.

2. Risser PG, Karr JR, Forman RTT (1984) Landscape ecology: directions and approaches. Special Publ. No. 2. Ill Nat Hist Surv Champaign, Ill.

3. Turner MG, Gardner RH (1991) Quantitative methods in landscape ecology: the analysis and interpretation of landscape heterogeneity. Springer-Verlag, New York, USA.

4. Pickett STA, Cadenasso ML (1995) Landscape ecology: spatial heterogeneity in ecological systems. Science 269: 331-334.

5. Ben-Natan G, Abramsky Z, Kotler BP, Brown JS (2004) Seeds redistribution in sand dunes: a basis for coexistence of two rodent species. Oikos 105: 325-335. 
Citation: Solomon AT (2018) Community Structure and Mechanisms of Co-existence among Six Guild Insect Species in the Munessa Forests. J Biodivers Endanger Species 6: 214. doi:10.4172/2332-2543.1000214

Page 7 of 7

6. Turner MG, O’Neill RV, Gardner RH, Milne BT (1989) Effects of changing spatial scale on the analysis of landscape pattern. Landscape Ecology 3: 153-162.

7. Turner MG (1990) Spatial and temporal analysis of landscape pattern. Landscape Ecology 4: 21-30.

8. Risser PG (1987) Landscape Ecology: State-of-the-Art 140: 3-14.

9. O'Neill RV, Krummel JR, Gardner RH, Sugihara G, Jackson B, et al. (1988) Indices of landscape pattern. Landscape Ecology 1: 153-162.

10. Ziv Y (1998) The effect of habitat heterogeneity on species diversity patterns: a community-level approach using an object-oriented landscape simulation model (SHALOM). Ecological Modelling 111: 135-170.

11. Wu J (2004) Effects of changing scale on landscape pattern analysis: scaling relations. Landscape Ecology 19: 125-138.

12. Turner MG (1989) Landscape ecology. Annual Review of Ecology and Systematics, USA.

13. Wu J, Shen W, Sun W, Tueller PT (2002) Empirical patterns of the effects of changing scale on landscape metrics. Landscape Ecology 17: 761-782.

14. Krummel JR, Gardner RH, Sugihara G, O'Neill RV, Coleman PR, et al. (1987) Landscape patterns in a disturbed environment. Oikos 48: 321-324.

15. Stenseth NC (1977) On the importance of spatio-temporal heterogeneity for the population dynamics of rodents: towards a theoretical foundation of rodent control. Oikos 29: 545-552.

16. Orians GH (1991) Preface. The American Naturalist 137: S1-S4.

17. Druce DJ (2005) Species requirements, coexistence and habitat partitioning at the community level: rock hyrax and klipspringer. University of KwaZulu-Natal, Durban- South Africa. pp: 122.

18. Therriault WT, Kolasa J (2000) Patterns of community variability depend on habitat variability and habitat generalists in natural aquatic microcosms. Community Ecology 1: 196-203.

19. Death RG (1995) Spatial patterns in benthic invertebrate community structure: products of habitat stability or are they habitat specific? Hydrobiologia 317: 97-107.

20. Abramsky Z, Strauss E, Subach A, Riechman A, Kotler BP (1996) The effect of barn owls (Tyto alba) on the activity and microhabitat selection of Gerbillus allenbyi and G. pyramidum. Oecologia 105: 313-319.

21. Ziv Y, Abramsky Z, Kotler BP, Subach A (1993) Interference competition and temporal and habitat partitioning in two gerbil species. Oikos 55: 237-246.

22. Rosenzweig ML (1991) Habitat selection and population interactions: the search for mechanism. Am Natur 137: S5-S28.

23. Levin AS, Paine TR (1974) Disturbance, patch formation, and community structure. Proc Nat Acad Sci 71: 2744-2747.

24. Tilman D (1988) Plant strategies and the dynamics and structure of plant communities. Princeton University Press, Princeton, NJ.
25. Melton DA (1987) Habitat selection and resource scarcity. South African journal of Science 83: 269-288.

26. Brown JS, Mitchell WA (1989) Diet selection on depletable resources Oikos 54: 33-43.

27. Shurin BJ, Amarasekar P, Jonathan M, Chase MJ, Robert D, et al. (2004) Alternative stable states and regional community structure. J Theor Bio 227: 359-368.

28. Taylor DL (1973) Some ecological implications of forest fire control in Yellowstone National Park, Wyoming. Ecology 54: 1394-1396.

29. Hansson L, Angelstam P (1991) Landscape ecology as a theoretical basis for nature conservation. Landscape Ecology 5: 191-201.

30. Wiens JA (1989) Spatial scaling in ecology. Func Ecol 3: 385-397.

31. Tadesse SA, Kotler BP (2014) Habitat quality and foraging ecology of mountain nyala (Tragelaphus buxtoni) in the Munessa Forest and the Bale Mountains National Park, south-eastern Ethiopia. Lap Lambert Academic Publishing, Saarbrücken, Germany. pp: 192.

32. Teketay D (1992) Human impact on a natural montane forest in southeastern Ethiopia. Mountain Resources Development 12: 393-400.

33. Teketay D, Granstrom A (1995) Soil seed banks in dry afro-montane forests of Ethiopia. J Veg Sci 6: 777-786.

34. Sugihara G, May RM (1990) Applications of Fractals in Ecology. Tree 5: 79-86.

35. Wiens JA, Stenseth NC, Van Horne B, Ims RA (1993) Ecological mechanisms and landscape ecology. Oikos 66: 369-380.

36. Milne BT (1988) Measuring the Fractal Dimension of Landscapes. Appl Math Comput 27: 67-79.

37. MacArthur RA, Wilson EO (1963) The theory of island biogeography Princeton Univ Press, Princeton.

38. Huston MA (1994) Biological diversity: the coexistence of species on changing landscapes. Cambridge, UK.

39. Schumacher HN (1996) Using landscape indices to predict habitat connectivity. Ecology 77: 1210-1225

40. Levins R (1969) Some demographic and genetic consequences of environmental heterogeneity for biological control. Bull Ent Soc Am 15: 237-240.

41. Gardner RH, Milne BT, Turner MG, O'Neill RV (1987) Neutral models for the analysis of broad-scale landscape pattern. Landscape Ecology 1: 19-28.

42. Milne BT (1991) Lessons from applying fractal models to landscape patterns. In: Turner M.G. and Gardner R.H. eds, quantitative methods in landscape ecology, pp: 199-235. Springer Verlag, New York, USA.

43. Burrough PA (1986) Principles of geographic information systems for land resources assessment. Oxford: Clarendon.

44. MacArthur RH, Levins R (1967) The limiting similarity, convergence and divergence of coexisting species. The American Naturalist 101: 377-385. 